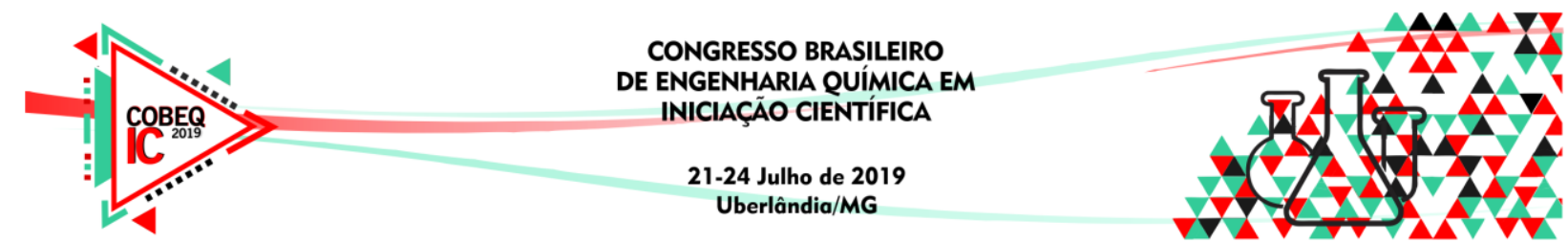

\title{
INFLUÊNCIA DA VAZÃO PULSADA NO ENXÁGUE DE DETERGENTE ALCALINO EM SISTEMA CIP (CLEAN IN PLACE)
}

\author{
W. V. PEREIRA JUNIOR ${ }^{1}$, L. D. SILVA ${ }^{1}$ e R. GEDRAITE ${ }^{1}$ \\ ${ }^{1}$ Universidade Federal de Uberlândia, Faculdade de Engenharia Química \\ E-mail para contato: rgedraite@ufu.br
}

\begin{abstract}
RESUMO - O clean in place (CIP) é uma técnica de higienização amplamente empregada em indústrias farmacêuticas e de alimentos. O procedimento é composto pela aplicação de detergente alcalino, enxágue, aplicação de detergente ácido, enxágue, sanitização e enxágue final. Neste trabalho foi avaliado o efeito das variáveis amplitude e período do fluxo pulsado sobre o consumo de água para enxágue e a consequente geração de efluente na etapa de enxágue do detergente alcalino utilizando vazão constante e vazões pulsadas. Os ensaios foram conduzidos em um protótipo de sistema CIP com detergente alcalino hidróxido de sódio e executados com base em um planejamento fatorial a dois níveis. Os resultados experimentais obtidos mostraram que ambas as variáveis, amplitude e período, são significativas em relação ao consumo de água. Além disso, verificouse que o enxágue com vazão pulsada pode produzir uma economia de aproximadamente 11,48 \% em relação a operação a vazão constante.
\end{abstract}

\section{INTRODUÇÃO}

A higienização clean in place (CIP) tornou-se uma prática comumente empregada em indústrias de alimentos. O processo CIP consiste em limpar os componentes de uma planta de processamento sem desmontar o equipamento, com pouco ou nenhum envolvimento manual do operador (Lelieveld et al., 2005). Em indústrias alimentícias, o procedimento de higienização CIP abrange as seguintes etapas: pré-enxaguar para remover as sujidades maiores do sistema; circular solução alcalina para solubilizar e dissolver depósitos protéicos da superfície e enxágüe intermediário com água para remover o detergente alcalino, seguido de circulação de solução ácida para remoção de depósitos minerais; enxágüe intermediário usando água potável para remover o ácido remanescente; sanitização para reduzir os microorganismos a níveis aceitáveis para os processamentos subsequentes e por fim enxágüe final para remoção dos agentes residuais (ANDRADE, 2008).

Esse processo gera grandes quantidades de efluentes contendo poluentes corrosivos, nutrientes e carga orgânica. As questões legislativas, a responsabilidade ambiental e a busca pela redução de custos potencializaram a busca por estratégias mais efetivas e parcimônicas para a limpeza CIP (Palabiyik, 2013). Desta forma, minimizar o consumo de água e consequentemente os efeitos ambientais é um ponto crítico para a indústria. A investigação de alternativas de limpeza são esforços constantes para melhorar significativamente 0 desempenho da higienização CIP (SILVA \& GEDRAITE, 2018). 


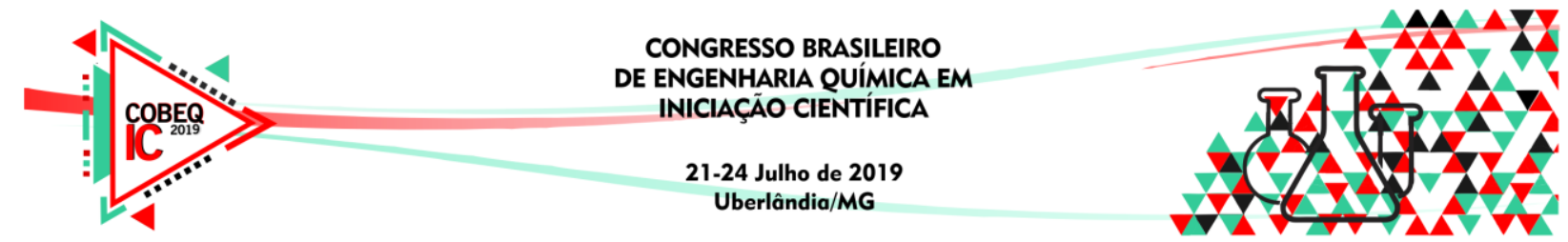

As aplicações industriais ainda estão limitadas às modificações mais simples em oposição às transformações mais complexas de equipamentos visto o custo envolvido e o tempo de retorno. É preferível mudanças simples na operação que produzam resultados significativos nos processos existentes. Portanto, otimizar a limpeza CIP com a modificação do fluxo se torna uma estratégia prática para muitas indústrias de alimentos, já que os operadores podem facilmente mudar e adaptar a dinâmica do fluxo no painel de controle (YANG et al., 2018).

O fluxo pulsado é caracterizado por um fluxo estacionário e um fluxo oscilante sobreposto. Silva e Gedraite (2018) relataram que o fluxo pulsado empregado na etapa de enxágue do detergente alcalino foi significativo na redução do volume de água gasto e no tempo despendido na operação.

Diante do exposto, o objetivo deste trabalho é avaliar o efeito da amplitude do pulso, o efeito da duração do período na operação enxágue do detergente alcalino utilizando vazão pulsada e comparar desempenho com o enxágue com vazão constante.

\section{MATERIAL E MÉTODOS}

A unidade experimental empregada neste estudo foi uma linha de circulação de leite com características semelhantes às observadas em indústrias de processamento de alimentos. A planta foi construída em aço inoxidável AISI 304, polimento \#4, com as mesmas condições de superfície para uso na indústria alimentícia. A linha de circulação pode ser vista na Figura 1. Foi utilizado como solução de limpeza, detergente alcalino, hidróxido de sódio $(\mathrm{NaOH})$ com concentração $0,5 \%(\mathrm{~m} / \mathrm{m})$ e água potável para enxágue do sistema.

Figura 1- Protótipo do sistema CIP.

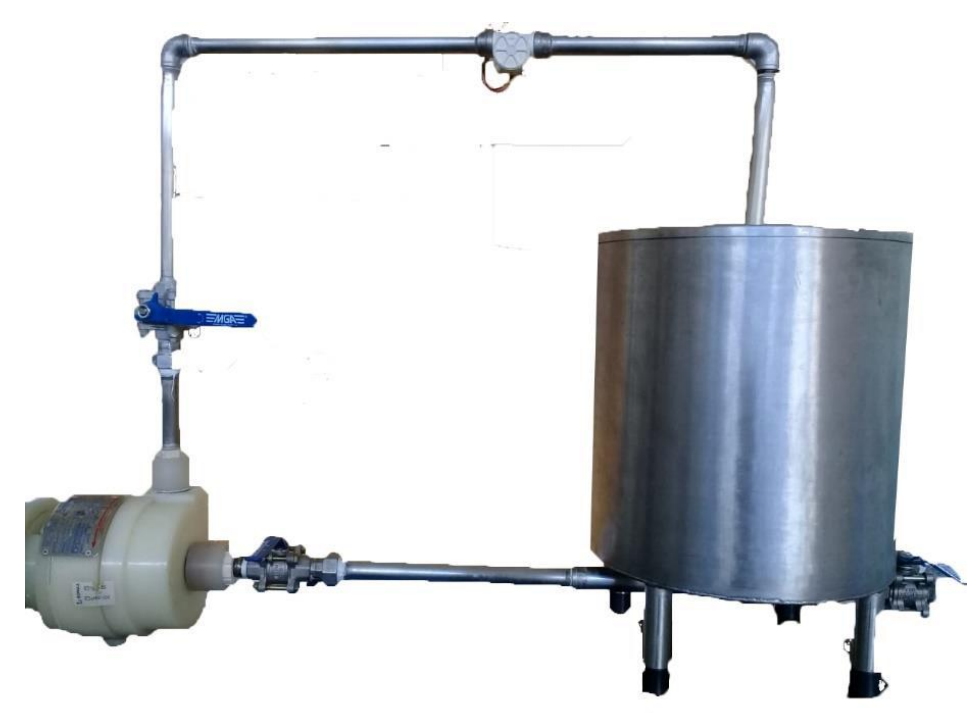




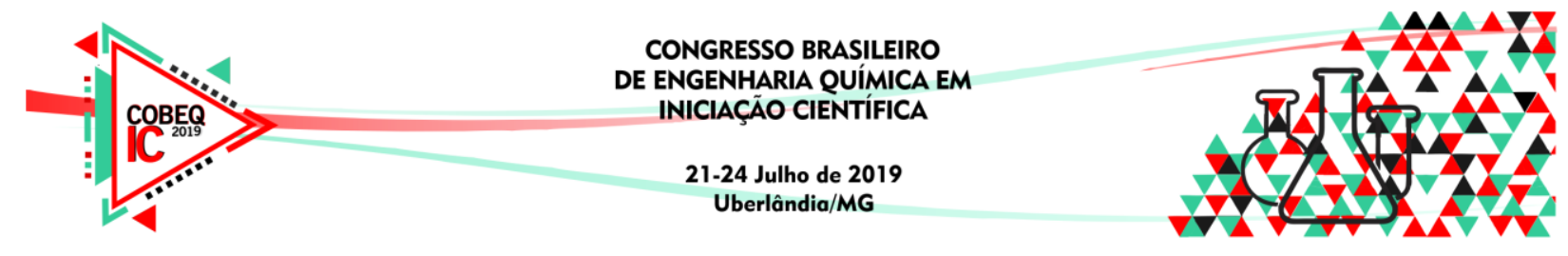

Para realizar a limpeza circulou-se detergente alcalino no protótipo por aproximadamente 30 minutos. Subsequentemente, a solução de detergente alcalino foi retirada do sistema, transferida para outro tanque e armazenada. Após essa etapa, água potável foi alimentada no tanque continuamente para promover o enxágue, a fim de representar adequadamente o cenário típico verificado nas instalações que usam esse tipo de limpeza.

Durante cada configuração de lavagem com detergente, monitorou-se a condutividade da água residual do protótipo. O processo de enxágue foi mantido até que a condutividade final atingiu o valor da água potável alimentada no tanque, sem variações em seu valor. Além disso, a remoção de hidróxido de sódio do sistema foi verificada por meio da reação do indicador de fenolftaleína para determinar a condição de parada.

Para calcular a quantidade de água gasta no enxágüe com as configurações propostas, o perfil de vazão com os valores coletados eletronicamente em função do tempo foi integrado, como mostrado na Equação 1. A divisão por 60 foi feita para corrigir as unidades, uma vez que a amostragem foi feita em segundos e a vazão foi apresentada em minutos.

$$
V=\frac{\int_{0}^{t} Q(t) d t}{60}
$$

Em que $Q(t)$ é a vazão em função do tempo e $V$ é o volume total gasto.

Para avaliar o efeito das variáveis sobre o consumo de água e consequentemente a quantidade de efluentes gerados com enxágüe foram investigadas configurações com fluxo pulsado variando a amplitude e período de pulso em dois níveis conforme mostrado na Tabela 1. Dessa forma, quatro configurações experimentais foram projetadas conforme mostrado na Tabela 2. Os experimentos foram realizados em duplicada, totalizando um total de oito experimentos executados. A análise estatística foi realizada no software Statistica.

Tabela 1 - Níveis das variáveis amplitude $\left(X_{1}\right)$ e período do pulso $\left(X_{2}\right)$.

\begin{tabular}{|c|c|c|}
\hline & -1 & 1 \\
\hline \hline$X_{1}$ : Amplitude (L/min) & 2,00 & 4,00 \\
\hline$X_{2}$ : Período (s) & 75 & 125 \\
\hline
\end{tabular}

Tabela 2 - Matriz de planejamento para enxágue com fluxo pulsado.

\begin{tabular}{|c|c|c|c|c|}
\hline \multirow{2}{*}{ Corridas } & \multicolumn{2}{|c|}{ Variáveis codificadas } & \multicolumn{2}{c|}{ Variáveis reais } \\
\cline { 2 - 5 } & $X_{1}$ & $X_{2}$ & Amplitude (L/min) & Período (s) \\
\hline \hline 1 & -1 & -1 & 2,00 & 75 \\
\hline 2 & 1 & -1 & 4,00 & 75 \\
\hline 3 & -1 & 1 & 2,00 & 125 \\
\hline 4 & 1 & 1 & 4,00 & 125 \\
\hline
\end{tabular}




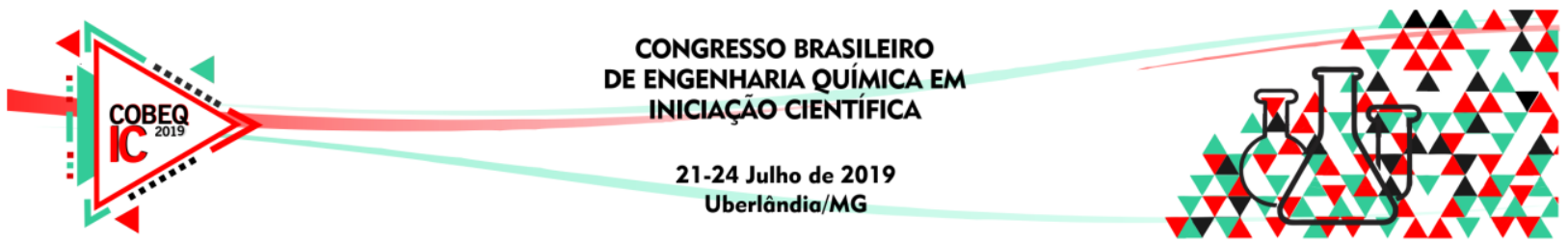

\section{RESULTADOS E DISCUSSÃO}

Com base nos experimentos descritos na metodologia, o volume de água gasto para cada configuração de enxágue são apresentados na Tabela 3.

Tabela 3 - Resultado médio do volume de água gasto para fluxo pulsado.

\begin{tabular}{|c|c|}
\hline Corrida & Volume (L) \\
\hline \hline 1 & $58,12 \pm 2,16$ \\
\hline 2 & $62,70 \pm 2,43$ \\
\hline 3 & $40,72 \pm 0,79$ \\
\hline 4 & $55,00 \pm 3,45$ \\
\hline
\end{tabular}

O resultado para análise da variância (ANOVA) é apresentado na Tabela 4. Nota-se que as ambas as variáveis do pulso, amplitude $(\mathrm{p}=0,0052)$ e período $(\mathrm{p}=0,0018)$ foram estatisticamente significativas, assim como a interação entre elas ( $\mathrm{p}=0,0463)$.

Tabela 4 - Resultado da ANOVA para volume de água gasto com fluxo pulsado.

\begin{tabular}{|c|c|c|c|c|c|}
\hline Fator & Soma dos Quadrados (SS) & GL & Quadrado Médio $(\mathrm{MS})$ & $\mathrm{F}$ & $\mathrm{p}$ \\
\hline \hline Amplitude $\left(X_{1}\right)$ & 177,8498 & 1 & 177,8498 & 30,7526 & 0,0052 \\
\hline Período $\left(X_{2}\right)$ & 315,0050 & 1 & 315,0050 & 54,4685 & 0,0018 \\
\hline Interação $\left(X_{I} \cdot X_{2}\right)$ & 47,0450 & 1 & 47,0450 & 8,1347 & 0,0463 \\
\hline Erro & 23,1330 & 4 & 5,7833 & & \\
\hline Soma dos Quadrados Total & 563,0328 & 7 & & & \\
\hline
\end{tabular}

A velocidade do fluxo tem uma influência substancial no comportamento de limpeza (Krause, 1993). A relevância do pulso pode ser atribuída ao aumento do gradiente de velocidade na tubulação que favorece a remoção do hidróxido. $O$ incremento da vazão favorece o fenômeno de turbulência na tubulação, de forma que o escoamento cresce do centro na direção radial na medida em que a velocidade média é aumentada (ANDRADE, 2008). Dessa forma, a parede do tubo experimenta uma maior tensão e redução da camada-limite, o que provoca aumento da taxa de transferência do fluido até a superfície e pode favorecer a retirada do detergente do sistema.

As experiências de Gillham et al., (2000) e Bode et al., (2007) também mostraram o potencial do fluxo pulsado na limpeza CIP para remoção de proteínas. Os autores relataram que a limpeza pode ser até $50 \%$ mais curta em relação ao tempo despendido quando o fluxo pulsado é aplicado.

O consumo de água com enxágüe realizado na vazão constante $(6 \mathrm{~L} / \mathrm{min})$ foi comparado com a operação realizada com fluxo pulsado na condição mais econômica, com vazão de $6 \mathrm{~L} / \mathrm{min}$ e amplitude de $2 \mathrm{~L} / \mathrm{min}$, período de 125 segundos. A Tabela 5 mostra a consumo comparativo entre os regimes de enxágue e a economia gerada. Observa-se que a economia registrada é estatisticamente significativa $(\mathrm{p}=0,0465)$ para as condições estudadas. 


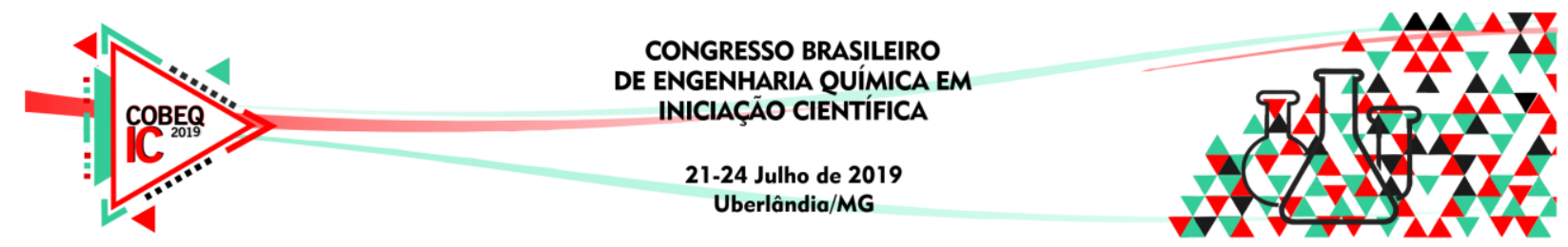

Tabela 5 - Comparativo entre o volume de água gasto.

\begin{tabular}{|c|c|c|c|}
\hline & Enxágue convencional & Enxágue pulsado & Economia \\
\hline \hline Volume (L) & $46,00 \pm 2,32$ & $40,72 \pm 0,79$ & 5,28 \\
\hline
\end{tabular}

Considerando que a operação de enxágue foi avaliada em um sistema com cerca de 1,2 metros de comprimento, e que esta etapa é realizada diariamente nas instalações industriais de processamento de alimentos, o enxágue com fluxo pulsado pode ser uma estratégia viável na higienização de superfícies já que as indústrias possuem tubulações de dimensões muito maiores, de forma que espera-se uma economia de água bastante significativa a longo prazo, assim como pode impactar na redução da carga de efluentes gerada.

\section{CONCLUSÃO}

Neste trabalho, investigou-se o enxágüe do detergente alcalino em um protótipo de sistema CIP, com características tipicamente encontradas na indústria de alimentos, usando fluxos pulsados para avaliar o efeito das variáveis amplitude e duração do pulso sobre o consumo de água e consequente geração de efluentes. Os resultados experimentais e a análise estatística indicaram que a magnitude da amplitude e duração do pulso aplicados são estatisticamente significativas para a economia de água. Assim, os resultados obtidos mostraram que o fluxo pulsado na etapa de enxágue do detergente alcalino pode reduzir o consumo de água e conseqüentemente a minimizar a quantidade de efluente gerada em cerca de 5,28 L em cada etapa de lavagem, representando economia de aproximadamente 11,48\% em relação à operação convencional.

\section{AGRADECIMENTOS}

Os autores agradecem à Universidade Federal de Uberlândia (UFU), Capes, CNPq e FAPEMIG (Fundação Apoio à Pesquisa do Estado de Minas Gerais) para os recursos concedidos no Projeto FAPEMIG No. TEC-APQ-02100-12.

\section{REFERÊNCIAS}

ANDRADE, N. J. D. Higiene na indústria de alimentos: avaliação e controle da adesão e formação de biofilmes bacterianos. São Paulo: Livraria Varela, 2008.

BODE, K., HOOPER, R.J., AUGUSTIN, W., PATERSON, W.R., WILSON, D.I., SCHOLL, S. Pulsed flow cleaning of whey protein fouling layers. Heat Transfer Engineering 28, 202-209. 2007.

GILLHAM, C. R.; FRYER, P. J.; HASTING, A. P. M; WILSON, D.I. Enhanced cleaning of whey protein fouling deposits using pulsed flows. J. Food Eng. (46): 199-209. 2000.

KRAUSE, S. Fouling of heat transfer surfaces by crystallization and sedimentation. International Journal of Chemical Engineering 33, 357-403. 1993. 
LELIEVELD, H.L.M., MOSTERT, M.A., HOLAH, J. Handbook of Hygiene Control in the Food Industry. Woodhead Publishing Limited, Cambridge, UK. 2005.

PALABIYIK, I. Investigation of Fluid Mechanical Removal in the Cleaning Process. School of Chemical Engineering, PhD thesis. University of Birmingham. 2013.

SILVA, L. D., \& GEDRAITE, R. Optimization of the CIP system enzyme stage for effluent reduction. Revista Eletrônica Em Gestão, Educação e Tecnologia Ambiental, 22, 12. 2018.

YANG, J., JENSEN, B. B. B., NORDKVIST, M., RASMUSSEN, P., GERNAEY, K. V., \& KRÜHNE, U. CFD modelling of axial mixing in the intermediate and final rinses of cleaning-in-place procedures of straight pipes. Journal of Food Engineering, 221, 95105. 2018. 